\title{
Seasonal variability of SST fronts and winds on the southeastern continental shelf of Brazil
}

\author{
Huan-Huan Chen ${ }^{1,2} \cdot$ Yiquan $_{\mathrm{Qi}^{2}}{ }^{2}$ Yuntao Wang $^{1}$ (D) $\cdot$ Fei Chai ${ }^{1,3}$
}

Received: 20 December 2018 / Accepted: 20 September 2019 / Published online: 28 October 2019

(C) The Author(s) 2019

\begin{abstract}
Fourteen years (September 2002 to August 2016) of high-resolution satellite observations of sea surface temperature (SST) data are used to describe the frontal pattern and frontogenesis on the southeastern continental shelf of Brazil. The daily SST fronts are obtained using an edge-detection algorithm, and the monthly frontal probability (FP) is subsequently calculated. High SST FPs are mainly distributed along the coast and decrease with distance from the coastline. The results from empirical orthogonal function (EOF) decompositions reveal strong seasonal variability of the coastal SST FP with maximum (minimum) in the astral summer (winter). Wind plays an important role in driving the frontal activities, and high FPs are accompanied by strong alongshore wind stress and wind stress curl. This is particularly true during the summer, when the total transport induced by the alongshore component of upwelling-favorable winds and the wind stress curl reaches the annual maximum. The fronts are influenced by multiple factors other than wind forcing, such as the orientation of the coastline, the seafloor topography, and the meandering of the Brazil Current. As a result, there is a slight difference between the seasonality of the SST fronts and the wind, and their relationship was varying with spatial locations. The impact of the air-sea interaction is further investigated in the frontal zone, and large coupling coefficients are found between the crosswind (downwind) SST gradients and the wind stress curl (divergence). The analysis of the SST fronts and wind leads to a better understanding of the dynamics and frontogenesis off the southeastern continental shelf of Brazil, and the results can be used to further understand the air-sea coupling process at regional level.
\end{abstract}

Keywords SST fronts $\cdot$ Wind stress $\cdot$ Wind stress curl $\cdot$ Air-sea interaction $\cdot$ Upwelling

\section{Introduction}

Oceanic fronts are narrow transitional zones of sharp horizontal gradient of different properties, including physical, chemical, and biological properties (temperature, salinity, density, and nutrients etc.) (Fedorov 1986; Belkin and O’Reilly 2009;

This article is part of the Topical Collection on the 10th International Workshop on Modeling the Ocean (IWMO), Santos, Brazil, 25-28 June 2018

Responsible Editor: Clemente Augusto Souza Tanajura

Yuntao Wang

yuntao.wang@sio.org.cn

1 State Key Laboratory of Satellite Ocean Environment Dynamics, Second Institute of Oceanography, Ministry of Natural Resources, Hangzhou, China

2 College of Oceanography, Hohai University, Nanjing, China

3 School of Marine Sciences, University of Maine, Orono, ME, USA
Belkin et al. 2009). According to the different dynamic processes, fronts can be divided into several types, including estuarine fronts, shelfbreak fronts, coastal upwelling fronts, and boundary current fronts (Belkin and O'Reilly 2009). Correspondingly, the sharp horizontal sea surface temperature (SST) gradient identified in ocean fronts is formed by several physical processes, including river outflows, tidal mixing, coastal and open ocean upwelling, and surface water convergence (Legeckis 1978). Lü et al. (2006) suggested that the estuarine front near the Yangtze River is affected by tidal mixing and freshwater river discharge. Fronts in western boundary currents, such as the Kuroshio Current, Gulf Stream, Brazil current (BC), and East Australia current, are formed because the temperature of the current is warmer than that of the ambient water as they flow to high latitudes (Belkin et al. 2009). Eastern boundary currents also have strong thermal fronts that are caused by wind-driven upwelling (Wang et al. 2015). Upwelling, which can be induced by the alongshore wind stress (Castelão and Wang 2014), wind stress curl (Pickett and Paduan 2003; Albert et al. 2010), bottom 
topography (Preller and O'Brien 1980; Rodrigues and Lorenzzetti 2001), coastline orientation (Hua and Thomasset 1983; Rodrigues and Lorenzzetti 2001), and other factors, is a particularly important process related to frontogenesis. When upwelling transports subsurface water upward, the temperature difference between the cold subsurface water and the warm offshore water results in a front (Olson and Backus 1985). A recent study has investigated other processes associating with upwelling that related with frontogenesis (Aguiar et al. 2018).

Fronts have important effects on oceanic dynamic processes because cross-front transport is limited, and the frontal zone is likely to be characterized by convergence (Bowman and Iverson 1978). Both convergence and upwelling can induce higher nutrient contents, which are generally associated with increased primary production (Acha et al. 2004). High fishery productivity is found in regions with strong frontal activities (Woodson and Litvin 2015).

Frontal activities are more prominent at middle latitudes, such as boundary current systems (Wang et al. 2015). The BC is the western boundary component of the subtropical circulation in the South Atlantic flowing southwestward along continental margin (Castro and Miranda 1998; Stramma and England 1999; Calado et al. 2008). Its water mass structure is dominated by warm tropical water $\left(\mathrm{T}>20^{\circ} \mathrm{C}, \mathrm{S}>36.40\right)$. Beneath BC, there is cold South Atlantic Central Water (SACW; $5{ }^{\circ} \mathrm{C}<\mathrm{T}<20^{\circ} \mathrm{C}, 34.3<\mathrm{S}<36.40$ ) at pycnocline levels (Castelão et al. 2004; Silveira et al. 2008; Palma and Matano 2009). And under the upwelling-favorable winds, the SACW can outcrop creating low SST in the surface (Palma and Matano 2009). The upwelling and thermal fronts off the southeastern continental shelf of Brazil are prominent in the vicinity of Cape Frio, especially during the astral summer (Castelão and Barth 2006). This region along the coast is characterized by a prevailing northeasterly wind field, which is favorable for upwelling in the Southern Hemisphere (Stech and Lorenzzetti 1992; Rodrigues and Lorenzzetti 2001; Castelão and Barth 2006; Palma and Matano 2009). During winter, the passage of cold atmospheric front highly influences the surface wind stress. Considering the wind stress is one of the important mechanisms of the coastal circulation, the cold front can also influence the variability of the flow. When the cold front approaches, the wind rotates from northeast to northwest direction in the back side of the front. One day after the passage of cold front, the southwest wind relaxes and returns back to northeast wind (Stech and Lorenzzetti 1992). However, the southwest wind is intense but not frequent, so the corresponding impact is less pronounced (Castelão 2012). The alongshore component of the northeasterly wind produces offshore Ekman transport, which leads to upwelling, especially in the vicinity of Cape Frio (Castro and Miranda 1998; Castelão 2012). The wind stress curl, induced by Ekman pumping, is also an important mechanism driving coastal upwelling along the coast near Cape Frio (Castelão and Barth 2006). Because the upwelling can carry cold water to the surface in the region near the coast, it is responsible for the development and maintenance of the SST front that separates cold water inshore from the offshore warm BC (Castelão 2012).

In addition to the wind-induced coastal upwelling, the upwelling near the shelfbreak off Cape Frio is also prominent. Rodrigues and Lorenzzetti (2001) suggested that variations in the vorticity caused by the curvature of the $\mathrm{BC}$ trajectory near Cape Frio are one of the key factors affecting the upwelling near the cape. The southward current has a large tendency to bend westward with the change of coastline orientation (Campos et al. 2000), which results in cyclonic eddies. Although the velocity and transport of the $\mathrm{BC}$ are weak compared with the Gulf Stream and the Kuroshio (Campos et al. 2013), the meandering of the $\mathrm{BC}$ and the change in coastline orientation result in higher eddy activity via baroclinic instability (Silveira et al. 2004). The resultant eddies have an important effect on driving upwelling (Calado et al. 2010). The changes in the bottom topography result in an alongshore bottom pressure gradient and generate onshore bottom flow via geostrophic processes (Palma and Matano 2009). The onshore flow subsequently induces shelfbreak upwelling, which enhances the frontal activities near the continental shelfbreak of Brazil. Thus, upwelling-favorable wind, eddies, and bottom topography are all favorable for driving upwelling and generating the SST front near Brazil (Silveira et al. 2008).

Over the past two decades, several studies have shown that in the oceans with strong SST fronts, the wind stress variables are significantly impacted by the SST (e.g., Chelton et al. 2004; Xie 2004). The fronts can impact the stability of the atmospheric boundary layer (Chelton et al. 2004). These studies found that when the surface wind blows over the warm water, the atmospheric boundary layer is deepened via enhanced vertical mixing, and momentum is pulled down from the upper atmospheric boundary layer to the ocean surface. The stability of the boundary layer will decrease, and the wind speed will increase (Small et al. 2008; Chelton and Xie 2010). However, the wind speed and wind stress decrease over cold water because of the increased stability of the atmospheric boundary layer separating the surface wind from the strong wind aloft (Xie 2004; Chelton et al. 2004; Kilpatrick et al. 2016). The spatial variation of the SST can result in a wind stress gradient, such as wind stress divergence (convergence) and a wind stress curl (Chelton and Xie 2010). If the wind blows along the front (across the front), the difference in the wind stress generates a wind stress curl (divergence). The full coupling process has been schematically described by Chelton et al. (2004) and further investigated around the global coastal oceans by Wang and Castelão (2016).

Air-sea interactions between the SST and wind stress have generally been identified in regions with strong frontal 
activities (Chelton et al. 2007; O'Neill et al. 2010). A linear relationship has been found between the wind stress curl (divergence) and crosswind (downwind) component of the SST gradient (e.g., Chelton et al. 2004; O'Neill et al. 2005; Chelton and Xie 2010). By modifying the wind stress field, the anomalously negative intensification of the wind stress curl is the result of enhanced SST fronts generated by anomalous upwelling (Castelão 2012). Therefore, the anomalies of the wind stress curl near Cape Frio are not only the cause of upwelling and the SST front but are also the result of them. This effect has been shown not only in the open ocean (e.g., Chelton et al. 2004; O'Neill et al. 2005, 2010) but also in coastal regions, including near capes (Chelton et al. 2007; Castelão 2012; Desbiolles et al. 2014; Wang and Castelão 2016). The strong frontal activities and coastal topography to the southeast of Brazil are favorable for the development of air-sea interactions, which can be important for understanding the local dynamics.

A previous study identified the SST fronts along the shelfbreak using 3 years of data from 2000 to 2002 (Lorenzzetti et al. 2009), and several studies have investigated the mechanisms of upwelling in the region offshore Brazil. However, without a long record of data to study the variability of the SST fronts in the coastal region and near the shelfbreak, the relation between SST fronts and wind forcing and the strength of the air-sea interaction are still unclear. In this study, 14 years of data are used to investigate the seasonal variability of SST fronts with a particular focus on the relationship between the wind and the SST fronts and the corresponding airsea interaction. The details of the data and methods we used are described in Section 2. Section 3 presents a description of the seasonal variability of the SST fronts and the wind forcing. In Section 4, the dynamics related to the upwelling and SST fronts are discussed with a summary of the key findings of this study.

\section{Data and methods}

The SST data are obtained from the Moderate Resolution Imaging Spectroradiometer (MODIS) onboard the Aqua satellite. Daily observations are available since 2002 . This study uses SST data from September 2002 to August 2016. The spatial resolution is approximately $4.5 \mathrm{~km}$, which can capture patterns at the mesoscale or less. The SST data are temporally replaced by the 3-day average to reduce the impact of clouds.

The SST fronts are obtained using an edge-detection algorithm (Canny 1986), and a brief description is presented here. The SST gradient vector is first calculated at each pixel. By tracking the SST gradient's direction, every pixel except the local maximum (non-maximum suppression) is suppressed. The pixels where the magnitude of the SST gradient is greater than a threshold $T_{1}$ are marked as frontal pixels. The algorithm then tracks the gradient magnitude until it is less than a smaller threshold $T_{2}$. The individual pixels whose SST gradient magnitudes are between $T_{2}$ and $T_{1}$ are identified as fronts. The two thresholds are set to $0.028^{\circ} \mathrm{T}$ and $0.014{ }^{\circ}$ a per kilometer, respectively, to ensure that they can capture most of the main fronts off southeastern Brazil. This method effectively prevents noisy edges from being decomposed into multiple edge segments. Legeckis (1978) described the fronts formed by different processes on a global scale by visually checking the SST images. Lately, different methods were developed to capture the location of such gradient by using a defined threshold (e.g., Kazmin and Rienecker 1996; Moore et al. 1997, 1999; Kostianoy et al. 2004; Breaker et al. 2005), using histogram (Cayula and Cornillon 1992, 1995, 1996), the Canny (1986) edge detector, and the Holyer and Peckinpaugh clustershadow method (e.g., Cayula et al. 1991) etc. Wang et al. (2015) used a revised Canny method for front detection in Eastern Boundary Currents Systems, and they captured the SST fronts in an accurate manner. One of the four eastern boundary currents systems, the Benguela Current, has similar meridional position of the SST fronts we studied in this paper, ranging between $14^{\circ} \mathrm{S}$ and $30^{\circ} \mathrm{S}$. The gradient field was also consistent between Benguela Current and Brazil Current. Thus, we adopted the same threshold to capture the SST fronts in the southeastern continental shelf of Brazil. For each location, we calculate the number of times that a pixel is identified as a front divided by the number of times that the pixel is free of clouds during certain time periods. This ratio yields a frontal probability (FP) for the corresponding period.

In this study, the FP is produced at a monthly interval to identify the temporal and spatial variability (e.g., Ullman and Cornillon 1999; Wang et al. 2015). To investigate the variability of the FP, an empirical orthogonal function (EOF) analysis is applied. Empirical orthogonal function (EOF) was first used in meteorology by Lorenz (1956), is one of the most widely used methods in atmosphere, ocean, and other sciences (Hannachi et al. 2007). This method decomposes a spacetime field into spatial patterns and associated time series, and each mode contains different spatial/temporal scales phenomena and thus can be isolated (Kaihatu et al. 1998). The method plays an important role in advancing our understanding of principal process. The temporal average of the time series at each grid is removed previously, followed by a spatial smooth average of FP at $3 \times 3$ grids to reduce noise. This method has been adopted and improved from Wang et al. (2015) where they accurately described SST front patterns in eastern boundary currents.

The wind data used in this study are the ERA-Interim reanalysis products, which are 4-dimensional variational analysis (4D-VAR) data developed by the European Center for Medium-Range Forecasts (ECMWF; Dee et al. 2011). The spatial resolutions of ERA-Interim reanalysis data range from 12 to $300 \mathrm{~km}$. In this paper, we used daily $10-\mathrm{m}$ wind data 
with $25-\mathrm{km}$ spatial resolution, which is available from 1979 to the present.

Two mechanisms are mainly responsible for wind-driven upwelling: the offshore Ekman transport driven by the alongshore wind and the Ekman pumping caused by the wind stress curl. First, we calculate the wind stress using the bulk formula. The alongshore wind stress is the alongshore component of the wind stress calculated as the dot product of the wind data approximately $150 \mathrm{~km}$ from the coast and a unit vector tangent to the local coastline (obtained by fitting a straight line to a radius of $50 \mathrm{~km}$ of the coastline centered on the coastal point). The wind stress curl is then calculated by forward difference.

$\vec{\tau}=\rho_{0} C_{D} \vec{V}|\vec{V}|$

Curl $=\frac{\partial v}{\partial x}-\frac{\partial u}{\partial y}$

where $\rho_{0}$ is the air density, $\vec{V}$ is the wind stress vector and 10 $\mathrm{m}$ wind vector, and the drag coefficient $C_{D}$ is calculated following Garratt (1977) as $C_{D=} 7.5 \times 10^{-4}+6.7 \times 10^{-5} \times|\vec{V}| . u$ and $v$ are the zonal and meridional components of wind stress; $x$ and $y$ are the locations in the zonal and meridional direction, respectively.

For the Ekman transport and Ekman pumping, we follow Pickett and Paduan (2003) and Castelão and Barth (2006) by using the monthly average alongshore wind stress and wind stress curl. The Ekman transport, $M$, is calculated from (Smith 1968):

$\mathrm{M}=\frac{1}{\rho f} \vec{\tau} \times k$

where the units of $M$ are $\mathrm{m}^{2} \mathrm{~s}^{-1}, \rho$ is the density of sea water $\left(1024 \mathrm{~kg} \mathrm{~m}^{-3}\right), f$ is the Coriolis parameter, $\vec{\tau}$ is the monthly average wind stress vector at the grids nearest the coast, and $k$ is the unit vector perpendicular to the coastline. We calculate the value of the Ekman transport at every coastal grid by multiplying the length $(\mathrm{m})$ of the corresponding coastline.

We calculate the velocity of the Ekman pumping, $w$, from (Smith 1968):

$w=\frac{1}{\rho f} \nabla \times \vec{\tau}$

where the units of $w$ are $\mathrm{m} / \mathrm{s}$, the transport induced by the Ekman pumping is obtained by multiplying $\mathrm{w}$ by each grid area $\left(\mathrm{m}^{2}\right)$ to an offshore distance of $150 \mathrm{~km}, \rho$ is the density of seawater, $f$ is the Coriolis parameter, and $\nabla \times \vec{\tau}$ is the monthly average wind stress curl.

Shi et al. (2015) found that the magnitude of the SST gradient was an indicator of SST fronts because it can describe the strength of the SST front. The monthly average SST gradient data and wind fields are used to investigate the air-sea interaction. The relationships between the wind stress curl and the crosswind component of the SST gradient and between the wind stress divergence and the downwind SST gradient are analyzed. The wind stress divergence is calculated as follows:

$\operatorname{Div}=\frac{\partial u}{\partial x}+\frac{\partial v}{\partial y}$

We focus on the period that the SST observation data and wind reanalysis data are available simultaneously (September 2002 to August 2016).

\section{Results}

\subsection{Average and seasonal evolution of frontal activity}

The average SST frontal probability and SST gradient magnitude of Brazil for the period from September 2002 to August 2016 are shown in Fig. 1. The spatial distribution of the FP is similar to that of the SST gradient magnitude in that large FPs are generally associated with large gradients. High values of the FP $(>6 \%)$ and SST gradient magnitude $\left(>2{ }^{\circ} \mathrm{C} / \mathrm{km}\right)$ are located between the coast and the shelf break, which approximately follows the $200-\mathrm{m}$ isobath. The corresponding values in the offshore regions are much less pronounced. The largest values of the FP in the offshore are found in the vicinity of the 200-m isobath, where the FPs exceed those in the coastal zone. This is particularly illustrated by a band of high FPs extending along the 200-m isobath from Vitoria (V) to the south. It is interesting to note that the offshore FP is significantly different to that in the coastal region to the north of Cape de Sao Tome (CST). The ambient FP increases to the south of CST, although the FP along the 200-m isobath can still be identified. The maximum FP is located to the southeast of Cape Frio (CF) and CST, where the FP is higher than $10 \%$. Two filaments of high values of the FP and SST gradient also can be observed along the northern boundary of a shoal near Caravelas (CA).

The FP along the southeastern continental shelf of Brazil shows strong seasonal variability, both spatially and temporally (Lorenzzetti et al. 2009). The seasonal average FP is characterized by large differences between the seasons (Fig. 2). During the spring, high FPs are mainly found over the shelf between V and SSI, though the intensity is weak (8\%). During the same period, the offshore FP is high (5\%). The FP reaches its annual maximum in the summer with large values $(10 \%$ and more) between V and SSI from the coast to the 200-m isobath. The frontal filament of CA also reaches its largest values during the summer. The FP near the coast weakens in the autumn, and the high FPs (approximately 9\%) are mainly distributed along the 200-m isobath from $\mathrm{V}$ to the southern edge of the study area. This spatial pattern persists to the 
Fig. 1 Climatological averages of (left) the frontal probability (FP, $\%)$ and (right) the SST gradient magnitude $\left({ }^{\circ} \mathrm{C}\right.$ per $\left.100 \mathrm{~km}\right)$ from September 2002 to August 2016 on the southeastern continental shelf of Brazil. The major cities and capes are labeled in the plots (CA, Caravelas; V, Vitoria; CST, Cape de São Tomé ; CF, Cape Frio; SSI, São Sebastião Island). The white lines represent the 200$\mathrm{m}$ isobath



winter, and the FPs along the 200-m isobaths decrease (7\%). The offshore FPs reach the annual maximum, though the values are still low (4\%) compared with those in the coastal regions.

The dominant patterns of SST frontal probability identified by empirical orthogonal function (EOF) decompositions are shown in Fig. 3. And the amplitude time series of EOF 1 and 2 are shown in Fig. 4. A general pattern of the FP is that large variability was found at seasonal scale, captured by EOF1, distributing in the coastal region (Fig. 3a). Although each EOF (EOF1 12.7\%, EOF2 5.9\%) explains a relatively small fraction of the total variance, they can explain the local variance (Chelton and Davis 1982) as large as 60\% and $40 \%$ in regions with large EOF magnitudes (not shown). The regions between V and SSI from the coast to the 200-m isobaths and to the north of CA are characterized by larger positive values for EOF1, indicating that seasonal variability is found in these regions. Combined the spatial patterns with the amplitude time series of the first EOF, it reveals that the seasonal enhancement of the SST FP occurs from late spring to summer (November-March) where the EOF1 values are positive and peaks in February. The maximum FP occurs in the astral summer, and it gradually weakens from the summer to the winter. After reaching the annual minimum in the winter, it reinforces in the following spring. In contrast, large negative values of EOF1 can be observed to the south of SSI near the 200-m isobath. In that region, the seasonal evolution of the FP is out of phase with the coastal region between V and SSI. The standard deviation of the monthly time series is large, indicating prominent intraseasonal variability, though much less predominant than seasonal variability. The second EOF of the FP mainly captures the frontal signal in the offshore region southeast of CF and CST characterized by weak positive magnitudes. The analysis of the amplitude of time series and monthly averaged time series of EOF2 also reveal clear seasonal variability that enhanced (depressed) offshore FPs from September to January (February to May), with peaks (troughs) in December (April). The periods with large amplitudes of EOF2, both positive and negative, are associated with large variances. There is large intraseasonal variability of the FP in the offshore regions.
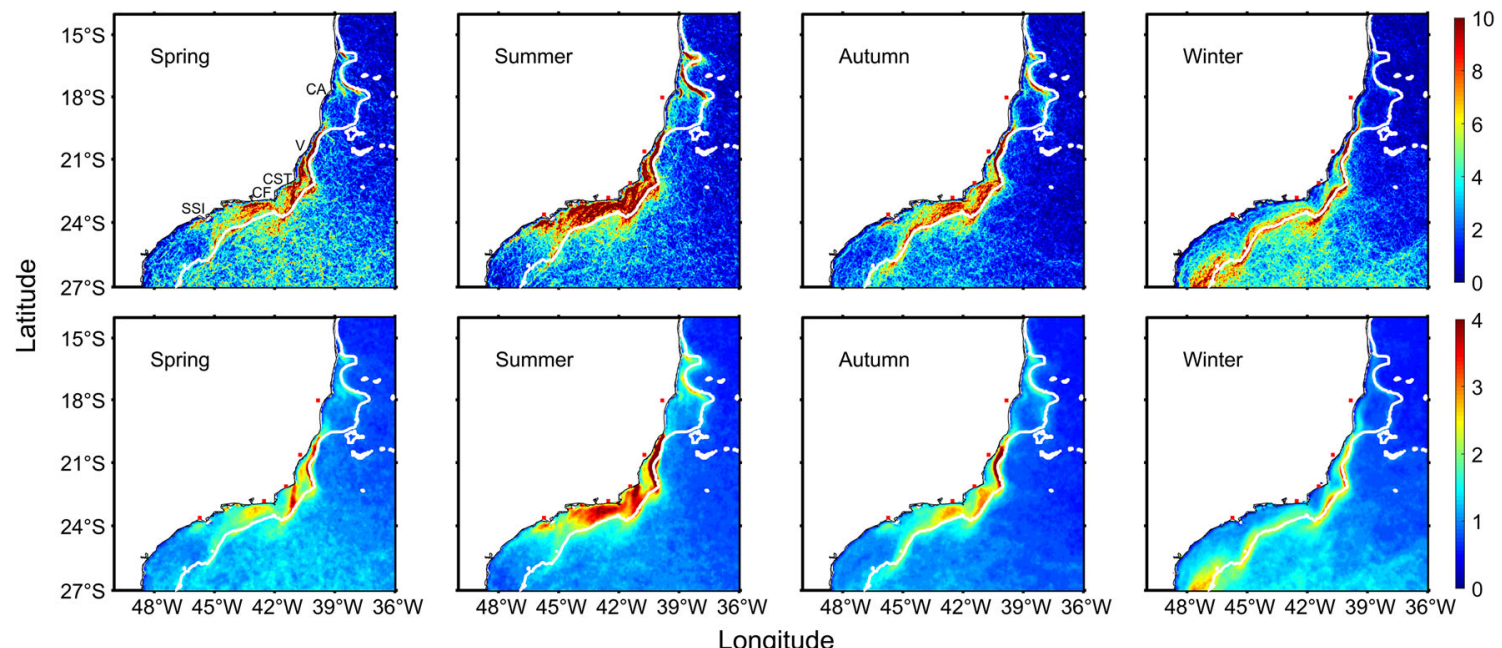

Fig. 2 Seasonal distributions of the FP (top) and SST gradient (bottom) averaged in the spring (September-November), summer (December-February), fall (March-May), and winter (June-August) 
Fig. 3 First (left) and second (right) EOF modes of SST frontal probability. The black box in the left panel represents the region used in Figs. 6, 7, and 8. The gray lines represent the 200-m isobath

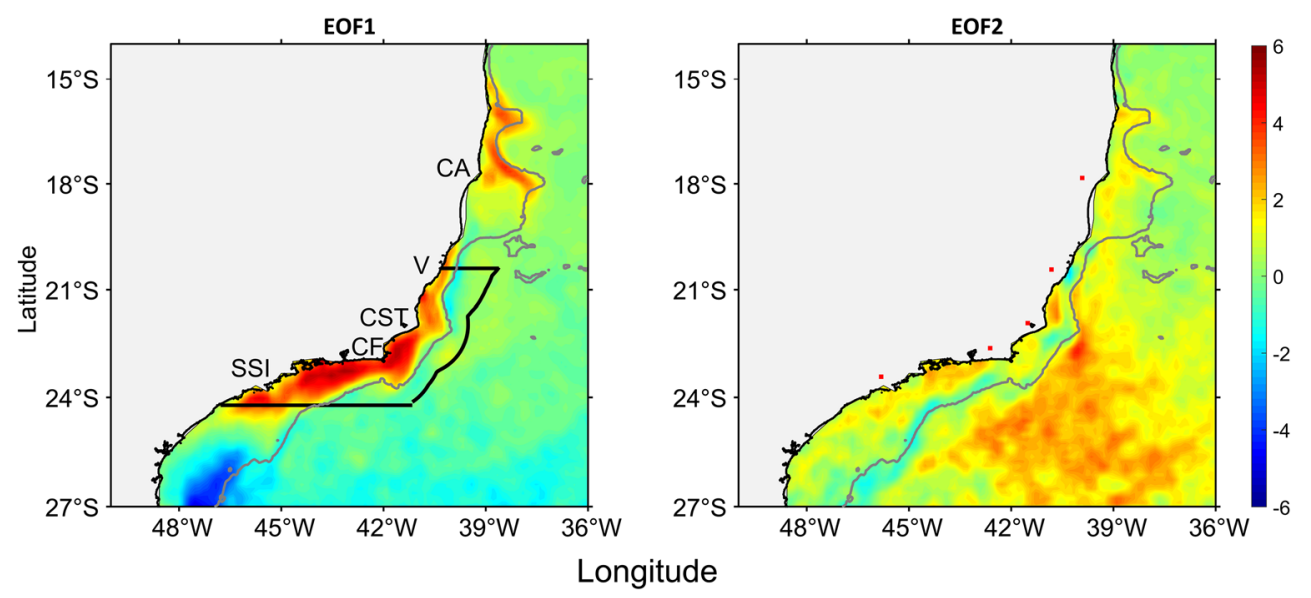

The combination of the first two EOFs shows that the FP is enhanced in the offshore region after September and the front over the shelf increases in November. The differences of front enhancement time indicate that the variability is not a result of offshore frontal migration. Thus, the mechanisms driving the offshore frontal variability are different in the coastal regions, which represented the unique feature of the region comparing with other boundary systems (Wang et al. 2015). In the coastal region, the SST FP shows obvious seasonal variability, but it is interesting to note that the FP along the shelf break near the $200-\mathrm{m}$ isobath is relatively persistent without a clear pattern of generation and disappearance, such as seasonal variability.

\subsection{Variability in the wind stress variables}

The region to the southeast of Brazil is dominated by northeasterly winds, which are favorable for upwelling. The seasonal averages of the wind stress and wind stress curl are shown in Fig. 5. The magnitudes of the wind speed and wind stress curl are strong in the astral spring and summer, and both are weakest in the fall. The wind stress to the north of $\mathrm{V}$ is generally weak, and it blows toward the west or northwest for most of the year (e.g., from fall to spring). The only exception is the summer, when the southwestward wind induces offshore Ekman transport, which can drive coastal upwelling
(Castelão and Wang 2014). The corresponding wind stress curl is also weak throughout the year, except to the south of $\mathrm{V}$, where a negative wind stress curl can be observed in the summer. The wind stress increases to the south of V, especially in the region between CF and CST, where the strongest wind stress for the entire region is observed. The strength of the wind stress in this region shows obvious seasonal variability with the maximum (minimum) occurring in the summer (fall). The highest wind stress is mainly located $100 \mathrm{~km}$ off the coast, which is approximately consistent with the 200-m isobath. The wind stress curl is consistently negative over the shelf between V and SSI with similar seasonality to the wind stress magnitude. However, the largest wind stress curl is found immediately next to the coast. To the west of SSI, the wind direction is persistently westward toward the coast throughout the year, though its magnitude changes in different seasons.

\subsection{Influence of the alongshore wind stress and wind stress curl on FP}

The spatial distribution of the FP is nearly identical to that of the wind stress curl, and the regions with the largest FP are characterized by the strongest wind (Figs. 3 and 5). Particularly in the region between V and SSI, the seasonal variability of the FP is highly consistent with the wind; large
Fig. 4 Amplitude time series for EOF1 (top) and EOF2 (bottom) of frontal probability. Values for monthly time series are shown on the left panels, while right panels show the monthly averages \pm 1 standard deviation

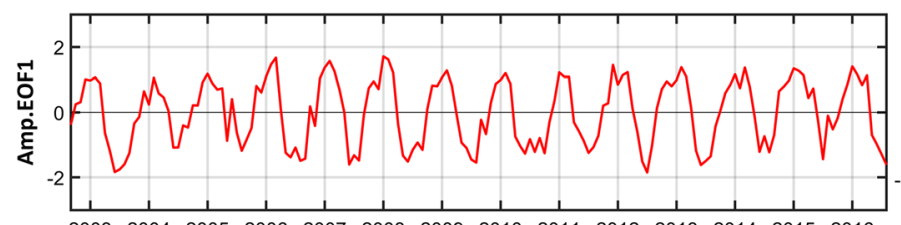

20032004200520062007200820092010201120122013201420152016
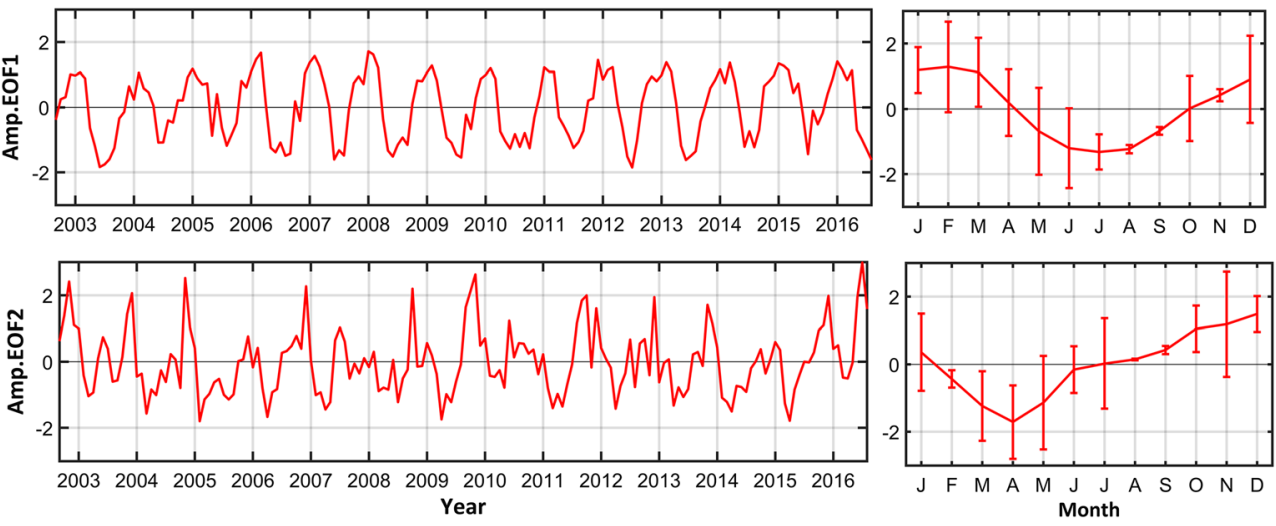

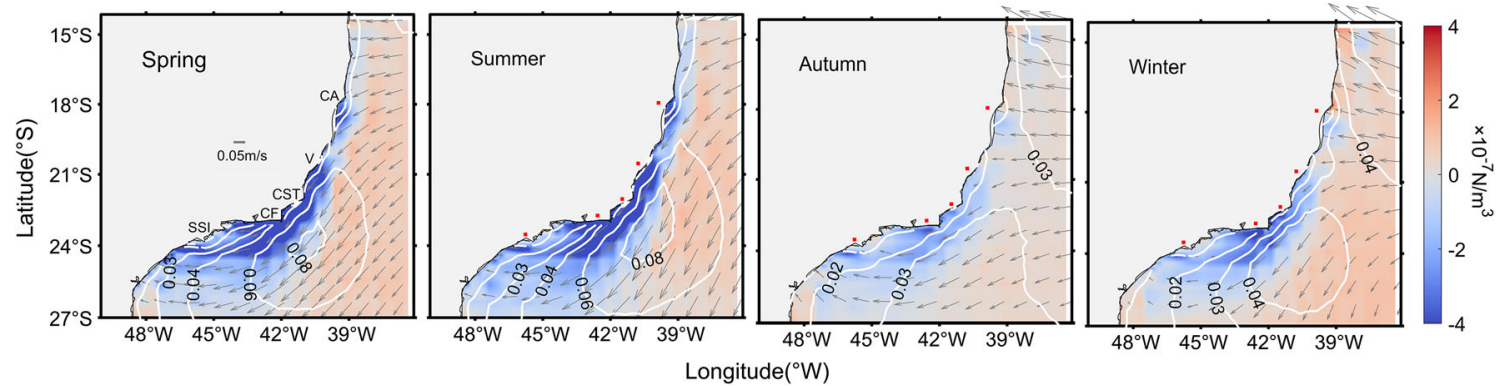

Fig. 5 Seasonal distribution of the wind stress magnitude (white contours) and wind stress curl (shading). The gray arrows indicate the wind speed and direction

FPs are always accompanied by strong wind stress and wind stress curl. Castelão and Wang (2014) and Wang et al. (2015) investigated the relationship between anomalous FP and anomalous alongshore wind stress in the eastern boundary current system. The anomalies were obtained by removing the corresponding long-term averages for each month; thus, the seasonal variability can be removed. These studies demonstrated that strong anomalies of upwelling-favorable wind stress may enhance the SST frontal activity because of the increased upwelling. We follow their approach and expand it to investigate the influence of the wind stress curl on driving fronts. Considering the strong effect of wind on SST fronts, we focus on the region where the SST fronts and wind have strong variations, which is denoted by the black box in Fig. 3 . Only the SST fronts and wind data within $150 \mathrm{~km}$ of the coast are used, and the northward alongshore wind stress is defined as positive. Scatterplots and linear regressions between the wind anomalies and FP anomalies are shown in Fig. 6. The correlation coefficient between the anomalies of the FP and the alongshore wind stress (wind stress curl) is $-0.55(-0.53)$, which is significant at the $99 \%$ confidence level. In this case, strong (weak) anomalies of upwelling-favorable wind stress and wind stress curl are accompanied by anomalously high (low) frontal activity.

The zonal averaged alongshore wind stress, wind stress curl, and SST frontal probabilities within $150 \mathrm{~km}$ of the coast are shown as functions of latitude in Fig. 7. The average FP along the coast shows two peaks: one is near CA and another is to the south of $\mathrm{V}$, though the value around $\mathrm{CA}$ is much lower than the second peak. The average alongshore wind stress increases gradually from the northern edge of the study area to SSI and then decreases to the south. The average wind stress curl is approximately zero to the north of CA. The negative wind stress curl is enhanced (upwelling-favorable) south of CA until it reaches its largest value around SSI. The spatial patterns of the alongshore wind stress and wind stress curl are generally consistent with the spatial average of the FP; e.g., the large FPs between $\mathrm{V}$ and SSI are associated with intense wind.

Although the spatial pattern of the FP is highly similar to the spatial distributions of the wind variables, and their anomalous fields are highly correlated, there are still inconsistencies between them. For example, the seasonal average FP decreases in the winter, but the weakest wind occurs in the fall. This difference suggests that the FP is not only influenced by the wind stress and wind stress curl but is also affected by other factors. For example, the front located S/SW of Cape Frio is induced by the meandering of the BC's path; thus, the resultant fronts are impacted less by the wind (Bentz et al. 2004; Lorenzzetti et al. 2006).

\subsection{Comparisons between Ekman transport and Ekman pumping}

The wind-induced frontogenesis is mainly related to vertical transport process, which includes two major processes: coastal upwelling induced by Ekman transport and Ekman pumping (Campos et al. 2013). The former is caused by the alongshore component of the wind stress, which induces offshore Ekman transport and forces the coastal deep water to move upward (Castelão and Barth 2006), and the latter is caused by the wind
Fig. 6 Scatterplots of the anomalies of the alongshore wind stress and FP (a) and wind stress curl and FP (b). The red lines are linear fits to the observations. The slopes $(s)$ of the regressions and the correlation coefficients $(r)$ are shown in the plots

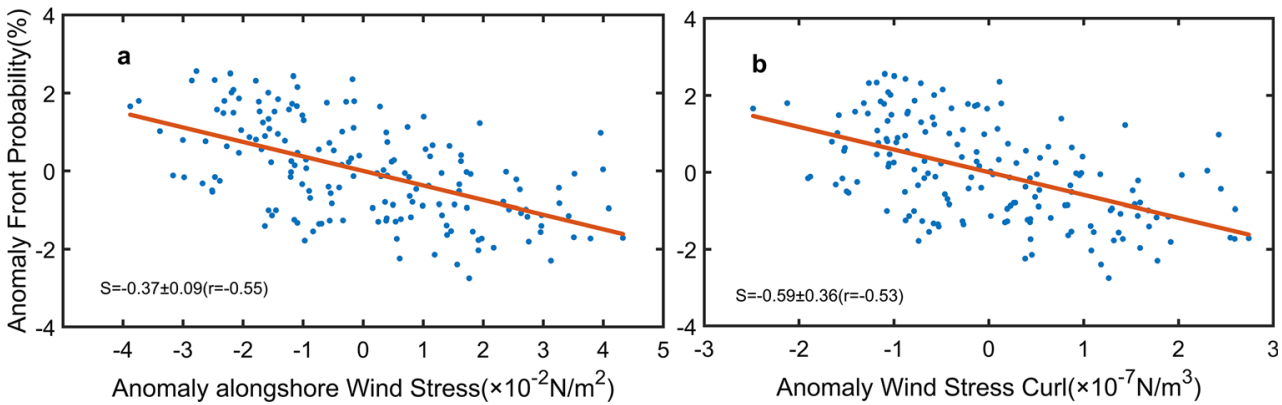


Fig. 7 Zonal averages of the coastal alongshore wind stress (blue line), wind stress curl (black line), and frontal probability (red line) along the southeastern continental shelf of Brazil. The spatial averages of the mean FP within $150 \mathrm{~km}$ of the coast are shown as a function of the latitude. The coastline and locations of major cities and capes are shown in the right panel. The dash-dotted lines are the 100-m and $1000-\mathrm{m}$ isobaths. The units of AWS, FP, and WSC are $\left(\times 10^{-2}\right) \mathrm{N} / \mathrm{m}^{2} 、 \%$, and $\left(\times 10^{-7}\right) \mathrm{N} /$ $\mathrm{m}^{3}$, respectively

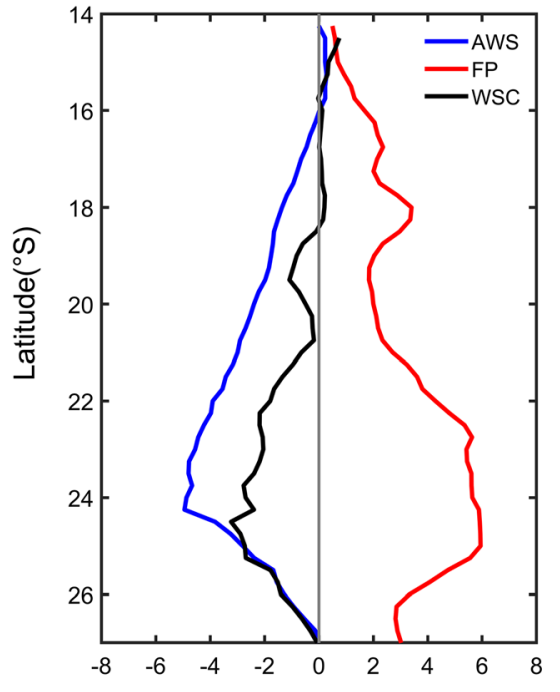

stress curl; a strong (weak) wind stress drives more (less) Ekman transport, and the differences in transport subsequently generate convergence or divergence in the area (Pickett and Paduan 2003). In the Southern Hemisphere, a negative wind stress curl can induce local upwelling via Ekman pumping.

The individual contributions of coastal upwelling induced by Ekman transport and Ekman pumping in the region from $\mathrm{V}$ to SSI are evaluated to investigate the importance of the alongshore wind stress and wind stress curl to the total upwelling. The Ekman transport is calculated as the summation of the transport at each grid point along the coast, whereas the Ekman pumping is integrated for the area within $150 \mathrm{~km}$ from coast. Figure 8 a shows the monthly averages of the Ekman transport and Ekman pumping and their total transport. Because the transport is based on the wind, both show the same seasonality as the wind variables. The largest transport consistently occurs from September to February, and the smallest value occurs in May. The magnitudes of the transport induced by both processes are similar, though the Ekman pumping is consistently greater than the Ekman transport. It is important to note that the transport is always positive, indicating that the monthly averaged wind direction and wind stress curl never reverse. Grouping the transport by season (Fig. 8b) shows that the seasonal variability is prominent; both transports reach their maximum during the spring and summer and their minimum in the fall. The total transport in the summer can be three times larger than that in the fall.

\subsection{Coupling between SST gradients and wind}

Coastal regions characterized by strong SST fronts often have strong air-sea interaction (Wang and Castelão 2016), and many studies have focused on quantifying the strength of the interaction (Chelton and Xie 2010). Coupling coefficients are considered to be indexes to gauge the responses of the wind stress curl to the crosswind SST gradient and of the wind stress divergence to the downwind SST gradient. The coupling relationship is identified in the anomaly field, which is obtained by removing the overall monthly average from the monthly time series (Chelton et al. 2007). The SST gradient is grouped into 14 bins, and the averages and standard deviations of the corresponding wind variables are calculated for all observations with gradients within each bin. The slope of the linear regression between the SST gradient bin and the corresponding average of the wind stress is subsequently defined as the coupling coefficient. Similar to before, we investigated the interaction between the SST gradient and the surface wind only in the region between V and SSI up to $150 \mathrm{~km}$ offshore, where the frontal activity is strong.

The linear regressions between the SST gradient and the wind stress are shown in Fig. 9. Both linear regressions are significant with positive coupling coefficients. The value for the relationship between the crosswind SST gradient and the wind stress curl is 1.92 , which is larger than that between the downwind SST gradient and the wind stress divergence. The range of the crosswind SST gradient is much larger than that of the downwind SST gradient. This is consistent with the fact that the wind direction is mainly along the front (Figs. 2 and 5); thus, the wind stress curl is substantially stronger than the divergence. We also split this analysis in two regions, one near the coast and another near the shelfbreak, the results show that the SST fronts have important effect on wind stress divergence and wind stress curl in both regions (figures not shown). In addition, the weak coupling coefficients between the downwind SST gradient and the wind stress divergence may be related to the reanalyzed wind dataset, which is smoothed to reduce abrupt downwind changes. 
Fig. 8. a Monthly vertical transports in the region denoted in Fig. 3 for the total transport (black), Ekman transport (blue), and Ekman pumping (red). b Average seasonal transports estimated for the Ekman transport (blue) and Ekman pumping (pink)
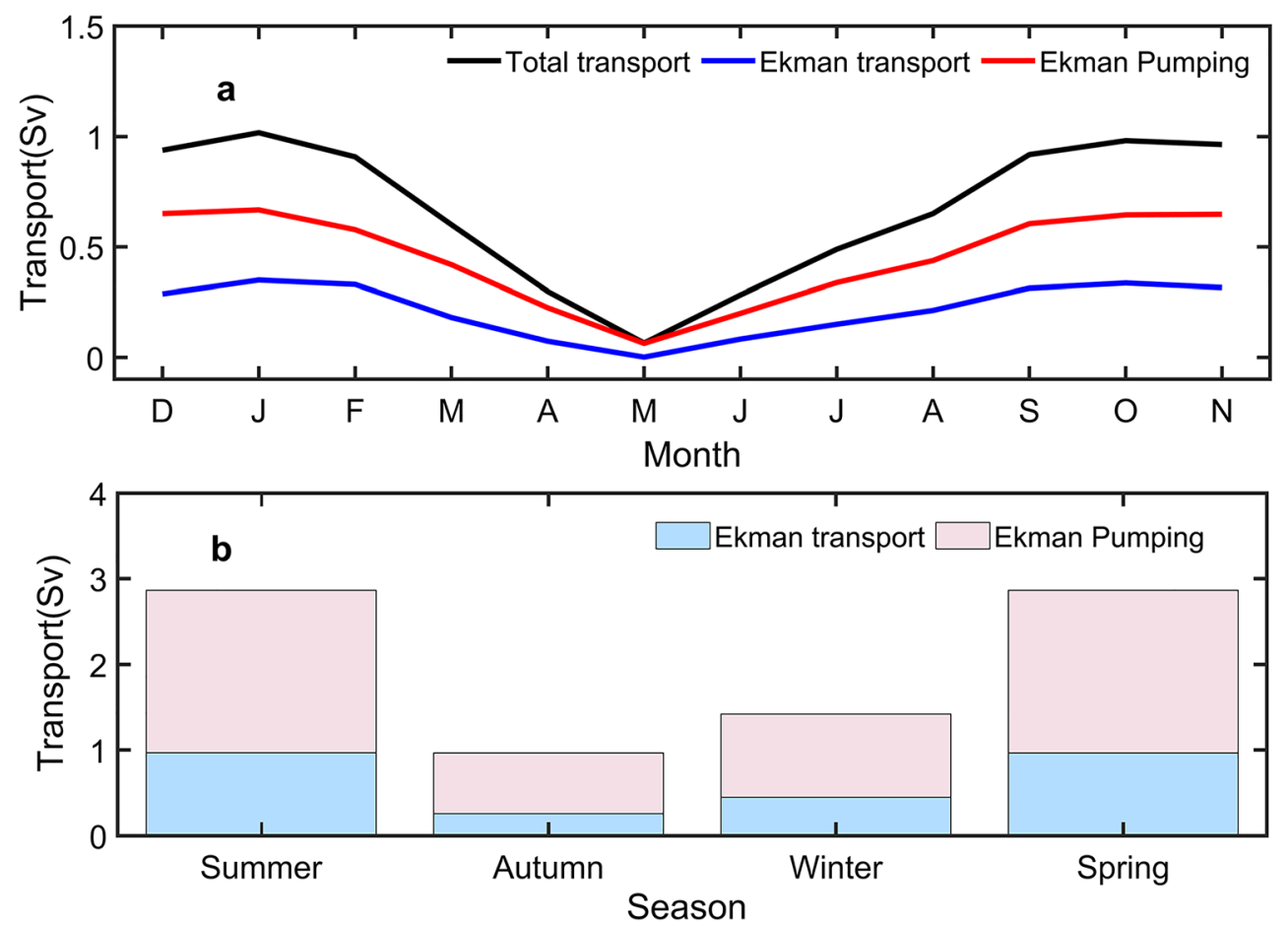

\section{Discussion}

Long-term observations of the SST and reanalyzed wind data from September 2002 to August 2016 are used to study the seasonal evolution of SST frontal activity and the relationship between the frontal activity and the wind variables along the southeastern continental shelf of Brazil. The coastal region is characterized by strong upwelling and frontal activity (Fig. 1). This region is dominated by northeasterly wind and a negative wind stress curl (Fig. 5), and both are favorable for upwelling in the Southern Hemisphere (Castelão 2012). The upwelling transports cold subsurface water to the surface and induces a front due to the contrast with the ambient warm water. Thus, the SST frontal activity is closely related to the alongshore wind stress and wind stress curl, both temporally and spatially (Figs. 2, 5, and 7). The temporal variabilities in the wind stress variables and SST frontal activity are mainly at seasonal scales (Figs. 2, 3, 4, and 5) with the largest values in the austral
Fig. 9 Linear regressions (a) between the crosswind SST gradient and wind stress curl and (b) between the downwind SST gradient and wind stress divergence for southeastern Brazil (denoted by the black box in Fig. 3). The vertical bars represent the standard deviation of the wind stress curl or divergence for each bin. The coupling coefficients are labeled in each panel
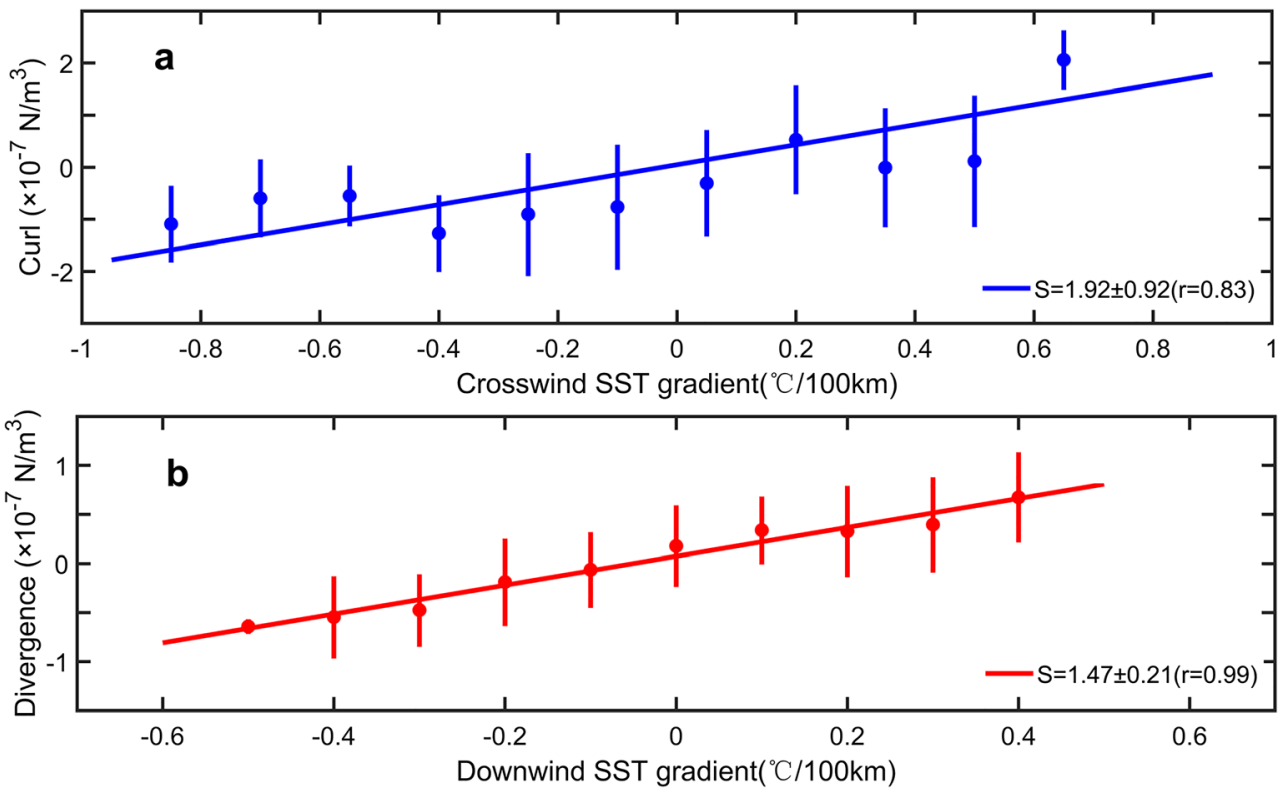
summer. Anomalous fields of the wind stress variables and FP are significantly correlated: the negative (positive) anomalous of wind stress and wind stress curl resulting in upwelling (downwelling) in the South Hemisphere. It indicates that the enhancement of the FP is often accompanied by strong upwelling-favorable winds (Fig. 6).

The wind-driven coastal upwelling and geostrophic shelfbreak upwelling are the dominant dynamics to the southeast of Brazil, particularly near CF (Palma and Matano 2009). From September to February, especially during the summer, the high values of the SST FP are mainly distributed along the coast and at the shelfbreak along the 200-m isobath. The strong northeasterly wind leads to offshore Ekman transport that induces divergence (Olson and Backus 1985). A comparison of the monthly averages of the Ekman transport and Ekman pumping shows that the latter is greater than the former by a factor of two, which indicates that the coastal region is also strongly impacted by a large negative wind stress curl (upwelling-favorable), especially in the summer. To the south of $\mathrm{CF}$, the bottom topography increases, which results in a northward pressure gradient. The pressure gradient force is balanced by the Coriolis force via onshore transport at depth (Palma and Matano 2009). The cold high-nutrient SACW is transported from the shelf to the coastal region near the bottom layer (Campos et al. 2000, 2013; Palma et al. 2008), and the wind forcing (e.g., offshore Ekman transport caused by northeasterly wind) enables the SACW to outcrop near the coast (Lorenzzetti et al. 2009). Campos et al. (2013) observed similar features using hydrographic measurements of $\mathrm{CF}$.

In addition, another front has been observed near the shelfbreak of Brazil, which is driven by other mechanisms. Campos et al. (2000) and Castelão et al. (2004) suggested that the instabilities of the $\mathrm{BC}$ caused by the abrupt change in the coastline orientation (Lorenzzetti et al. 2009) can induce meanders and eddies that lead to shelfbreak upwelling. Palma and Matano (2009) showed that the changes in the alongshore bottom topography modify the meridional pressure gradient and that the resultant pressure gradient induces onshore bottom flow and subsequently drives shelfbreak upwelling. In either case, the SST front near the shelfbreak is less dependent on the wind pattern and thus is persistent for the entire year. The wind weakens in the fall and winter, and the corresponding coastal SST front diminishes, which makes the shelfbreak SST front more prominent (Fig. 2).

The comparison between the FP and wind forcing indicates that they are closely related, but the difference in seasonality is prominent. This is because the SST front is controlled not only by wind but also by other mechanisms, such as the bottom topography and irregular coastline. Previous studies showed that the variations in Peruvian coastal upwelling were associated with the bottom topography (Preller and O'Brien 1980). Hua and Thomasset (1983) indicated that the upwelling in the Gulf of Lions was only dependent on the coastline geometry.
Rodrigues and Lorenzzetti (2001) suggested that on the Brazilian southeast continental shelf, both the coastline geometry and the bottom topography influence the magnitude and location of frontal activity. To the south of CST, the irregular coastline is a key factor that controls the intensity of upwelling, whereas north of CST, the magnitude of upwelling is controlled by the bottom topography and wind intensity. This difference occurs because the depth is only approximately $30 \mathrm{~m}$ near CST, and the bottom stress induces dissipation of the vorticity generated by the cape (Rodrigues and Lorenzzetti 2001). A similar phenomenon was identified along the coast of Oregon, where the upwelling near a major cape is related to the bottom topography rather than the coastline direction (Peffley and O'Brien 1976). In contrast, the bottom stress near $\mathrm{CF}$, where the depth is approximately $70 \mathrm{~m}$, plays an insignificant role in the local dynamics, but the significant change in coastline direction influences the generation of vorticity off CF (Campos et al. 2000).

The offshore region with high frontal activity is an important feature that describes the area where front activities are important. The width of the region with high FPs is determined by multiple factors, particularly the width of the shelf. For example, a larger shelf is generally associated with high FPs extending for greater offshore distances (Wang et al. 2015). High values of the SST frontal probabilities and SST gradient are mainly distributed along the coast from V to SSI and extend approximately $100 \mathrm{~km}$ from the coast. The continental shelf of $\mathrm{V}$ is narrow (only approximately $50 \mathrm{~km}$ ) and extends to approximately $80 \mathrm{~km}$ off CF (Rodrigues and Lorenzzetti 2001). Similarly, the width of the SST front with high values increases from $\mathrm{V}$ to $\mathrm{CF}$, and the corresponding width of the area with large FPs also increases from 50 to $150 \mathrm{~km}$. Because the continental shelf is narrow and steep north of $\mathrm{CF}$, the fronts are mainly located near the coast. To the south of $\mathrm{CF}$, the coastline abruptly changes from northsouth to east-west and the shelf also shrinks. Similarly, the region with high FPs becomes closer to the coast, indicating that the $\mathrm{BC}$ tends to be closer to the shoreline (Campos et al. 2000) and occasionally intrudes onto the continental shelf (Stech and Lorenzzetti 1992; Campos et al. 2000, 2013).

Air-sea interactions are prominent in regions characterized by large frontal activities (Haack et al. 2008) with strong wind stress (Spall 2007; O'Neill et al. 2010), either in the open ocean or the coastal ocean. Coupling coefficients have been used to gauge the strength of the coupling in coastal regions around the world (Wang and Castelão 2016). Previous studies found that the coupling coefficients between the wind stress divergence and the downwind SST gradient are usually larger than those between the wind stress curl and the crosswind SST gradient (O'Neill et al. 2005; Haack et al. 2008; O'Neill 2012). This is partly because the variations in the wind direction gradient induced by the SST enhance the divergence and reduce the curl response (O'Neill et al. 2010). In addition, the 
current can affect the wind stress curl more than the wind stress divergence because ocean currents are nearly nondivergent (Chelton and Xie 2010). However, this study found that the coupling coefficient for the divergence field is smaller than that of the curl field using ECMWF data. This result was confirmed by using the same approach with another dataset (e.g., QuikSCAT data; the results are not shown here) and is consistent with Wang and Castelão (2016). This may be because the wind direction in this region is more stable, blowing from the northeast for nearly the entire year, and only occasionally reverses in the astral winter. Because the wind direction is mainly parallel to the front, the crosswind SST gradient results in larger responses for the wind stress curl. The wind stress curl and divergence induced by the SST affect the vertical motions of water, which can provide feedback to the ocean. For example, the Ekman pumping, which is driven by the wind stress curl, generates ocean currents and local upwelling that can modify the SST (Chelton and Xie 2010).

Several studies have shown that the enhancement of the upwelling region along the coast due to the greenhouse effect generally strengthens the wind-driven upwelling in coastal upwelling regions around the world (Bakun et al. 2010). Long-term observations of the Benguela Current System also reveal the enhancement of upwelling associated with the upwelling-favorable wind (Santos et al. 2012). This may lead to an increase in the SST gradient in the upwelling boundary region. No robust trend was found in our study, but the upwelling features and the associated frontal activities of Brazil are expected to be enhanced due to the impact of global changes. Using a time series of approximately 30 years, Kahru et al. (2012) showed that the SST and chlorophyll fronts in the California Current System have a significant decadal increasing trend. Therefore, it would be interesting to investigate whether the same trend exists on the southeastern continental shelf of Brazil.

Finally, this study reveals that the alongshore wind stress and wind stress curl play important roles in the SST fronts and that other mechanisms also influence the local dynamics. Numerical modeling can be used to simulate the dynamic processes and the related frontogenesis. It will be important to quantify the influence of each factor on SST frontal activity in the southeastern continental shelf of Brazil to improve our understanding of local hydrodynamical processes.

In summary, 14 years of observations and analysis data are used to describe the seasonal variation and spatial distribution of SST fronts along the Brazilian coast. The frontal activities are compared with the wind fields to quantify their relationship. The frontal characteristics in this area show strong seasonal variations from $\mathrm{V}$ to $\mathrm{SSI}$, which is consistent with the coastal wind stress and wind stress curl. The frontal probabilities increase mainly near the capes. The strong front activity is often accompanied by strong prevailing winds that favor upwelling. In addition to the wind forcing, the bottom topography, the irregular coastline, and the curvature of the Brazil Current all have important influences on the frontogenesis. The influences of the different mechanisms on the fronts should be further quantified by hydrodynamical models and detailed observations. In addition, longer time series should be used to study the decadal-scale variability and long-term trend of the frontal activity.

Acknowledgments We are very thankful to the National Aeronautics and Space Administration (NASA) for sharing the satellite dataset (https:// podaac-tools.jpl.nasa.gov/) and the European Center for Medium-Range Weather Forecasts (ECMWF) for releasing the ERA-Interim reanalysis product.

Funding information The study is financially supported by the National Natural Science Foundation of China (Nos. 41806026, 41890805, and 41730536), and the Project of State Key Laboratory of Satellite Ocean Environment Dynamics, Second Institute of Oceanography (No. SOEDZZ1902).

Open Access This article is distributed under the terms of the Creative Commons Attribution 4.0 International License (http:// creativecommons.org/licenses/by/4.0/), which permits unrestricted use, distribution, and reproduction in any medium, provided you give appropriate credit to the original author(s) and the source, provide a link to the Creative Commons license, and indicate if changes were made.

\section{References}

Acha EM, Mianzan HW, Guerrero RA, Favero M, Bava J (2004) Marine fronts at the continental shelves of austral South America: physical and ecological processes. J Mar Syst 44(1-2):83-105

Aguiar AL, Cirano M, Marta-Almeida M, Lessa GC, Valle-Levinson A (2018) Upwelling processes along the South Equatorial Current bifurcation region and the Salvador Canyon ( $\left.13^{\circ} \mathrm{S}\right)$, Brazil. Cont Shelf Res 171:77-96

Albert A, Echevin V, Lévy M, Aumont O (2010) Impact of nearshore wind stress curl on coastal circulation and primary productivity in the Peru upwelling system. J Geophys Res Oceans 115:C12033. https://doi.org/10.1029/2010JC006569

Bakun A, Field DB, Redondo-Rodriguez ANA, Weeks SJ (2010) Greenhouse gas, upwelling-favorable winds, and the future of coastal ocean upwelling ecosystems. Glob Chang Biol 16(4):1213-1228

Belkin IM, O'Reilly JE (2009) An algorithm for oceanic front detection in chlorophyll and SST satellite imagery. J Mar Syst 78(3):319-326

Belkin IM, Cornillon PC, Sherman K (2009) Fronts in large marine ecosystems. Prog Oceanogr 81:223-236

Bentz CM, Lorenzzetti JA, Kampel M (2004) Multi-sensor synergistic analysis of mesoscale oceanic features: Campos Basin, southeastern Brazil. Int J Remote Sens 25(21):4835-4841

Bowman M, Iverson R (1978) Estuarine and plume fronts. In: Bowman MJ, Esaias WE (eds) Oceanic fronts in coastal processes, pp 87-104

Breaker LC, Mavor TP, Broenkow WW (2005) Mapping and monitoring large-scale ocean fronts off the California Coast using imagery from GOES-10 geostationary satellite. Publication T-056, California Sea Grant College Program, University of California, San Diego. 25 pp. http://repositories.cdlib.org/csgc/rcr/Coastal05 02. Accessed 2005

Calado L, Gangopadhyay A, Silveira ICA (2008) Feature-oriented regional modeling and simulations (FORMS) for the western South Atlantic: Southeastern Brazil region. Ocean Model 25:48-64 
Calado L, Da Silveira ICA, Gangopadhyay A, De Castro BM (2010) Eddy-induced upwelling off Cape São Tomé (22 S, Brazil). Cont Shelf Res 30(10-11):1181-1188

Campos EJ, Velhote D, da Silveira IC (2000) Shelf break upwelling driven by Brazil Current cyclonic meanders. Geophys Res Lett 27(6):751-754

Campos PC, Möller OO Jr, Piola AR, Palma ED (2013) Seasonal variability and coastal upwelling near Cape Santa Marta (Brazil). J Geophys Res Oceans 118(3):1420-1433

Canny JA (1986) Computational approach to edge detection. IEEE Trans Pattern Anal Mach Intell PAMI-8:679-698

Castelão RM (2012) Sea surface temperature and wind stress curl variability near a cape. J Phys Oceanogr 42(11):2073-2087

Castelão RM, Barth JA (2006) Upwelling around Cabo Frio, Brazil: the importance of wind stress curl. Geophys Res Lett 33:L03602. https://doi.org/10.1029/2005GL025182

Castelão RM, Wang Y (2014) Wind-driven variability in sea surface temperature front distribution in the California Current System. J Geophys Res Oceans 119(3):1861-1875

Castelão RM, Campos EJ, Miller JL (2004) A modelling study of coastal upwelling driven by wind and meanders of the Brazil Current. J Coast Res 203(3):662-671

Castro BD, Miranda LD (1998) Physical oceanography of the western Atlantic continental shelf located between $4^{\circ} \mathrm{N}$ and $34^{\circ} \mathrm{S}$. The Sea 11(1):209-251

Cayula JF, Cornillon P (1992) Edge detection algorithm for SST images. J Atmos Ocean Technol 9(1):67-80

Cayula JF, Cornillon P (1995) Multi-image edge detection for SST images. J Atmos Ocean Technol 12(4):821-829

Cayula JF, Cornillon P (1996) Cloud detection from a sequence of SST images. Remote Sens Environ 55(1):80-88

Cayula JF, Cornillon P, Holyer R, Peckinpaugh S (1991) Comparative study of two recent edge-detection algorithms designed to process sea-surface temperature fields. IEEE Trans Geosci Remote Sens 29(1):175-177

Chelton DB, Davis R (1982) Monthly mean sea-level variability along the west coast of North America. J Phys Oceanogr 12:757-784

Chelton DB, Xie S (2010) Coupled ocean-atmosphere interaction at oceanic mesoscales. Oceanography 23(4):52-69

Chelton DB, Schlax MG, Freilich MH, Milliff RF (2004) Satellite measurements reveal persistent small-scale features in ocean winds. Science 303(5660):978-983

Chelton DB, Schlax MG, Samelson RM (2007) Summertime coupling between sea surface temperature and wind stress in the California Current System. J Phys Oceanogr 37(3):495-517

Dee DP, Uppala SM, Simmons AJ et al (2011) The ERA-interim reanalysis: configuration and performance of the data assimilation system. Q J R Meteorol Soc 137:553-597

Desbiolles F, Blanke B, Bentamy A, Grima N (2014) Origin of fine-scale wind stress curl structures in the Benguela and Canary upwelling systems. J Geophys Res Oceans 119(11):7931-7948

Fedorov KN (1986) The physical nature and structure of oceanic fronts. Lecture Notes on Coastal and Estuarine Studies Series, Volume 19. https://doi.org/10.1002/9781118669266.ch0

Garratt JR (1977) Review of drag coefficients over oceans and continents. Mon Weather Rev 105(7):915-929

Haack T, Chelton D, Pullen J, Doyle JD, Schlax M (2008) Air-sea interaction from US west coast summertime forecasts. J Phys Oceanogr 38:2414-2437

Hannachi A, Jolliffe IT, Stephenson DB (2007) Empirical orthogonal functions and related techniques in atmospheric science: a review. Int J Climatol 27(9):1119-1152. https://doi.org/10.1002/joc.1499

Hua BL, Thomasset F (1983) A numerical study of the effects of coastline geometry on wind-induced upwelling in the Gulf of Lions. J Phys Oceanogr 13(4):678-694
Kahru M, Di Lorenzo E, Manzano-Sarabia M, Mitchell BG (2012) Spatial and temporal statistics of sea surface temperature and chlorophyll fronts in the California Current. J Plankton Res 34(9):749760

Kaihatu JM, Handler RA, Marmorino GO, Shay LK (1998) Empirical orthogonal function analysis of ocean surface currents using complex and real-vector methods*. J Atmos Ocean Technol 15(4):927941

Kazmin AS, Rienecker MM (1996) Variability and frontogenesis in the large-scale oceanic frontal zones. J Geophys Res 101(C1):907-921

Kilpatrick T, Schneider N, Qiu B (2016) Atmospheric response to a midlatitude SST front: Alongfront winds. J Atmos Sci 73(9): 3489-3509

Kostianoy AG, Ginzburg AI, Frankignoul M, Delille B (2004) Fronts in the southern Indian Ocean as inferred from satellite sea surface temperature data. J Mar Syst 45(1-2):55-73

Legeckis R (1978) A survey of worldwide sea surface temperature fronts detected by environmental satellites. J Geophys Res Oceans 83(C9): $4501-4522$

Lorenz EN (1956) Empirical orthogonal functions and statistical weather prediction. Technical report, Department of Meteorology, MIT, Science Report 1

Lorenzzetti JA, Kampel M, Bentz CM, Torres Jr AR (2006) A Mesoscale Brazil Current frontal eddy: observations by ASAR, RADARSAT-1 complemented with visible and infrared sensors, in situ data and numerical modeling. Advances in SAR Oceanography from Envisat and ERS Missions, Proceedings of SEASAR, 23-26

Lorenzzetti JA, Stech JL, Mello Filho WL, Assireu AT (2009) Satellite observation of Brazil Current inshore thermal front in the SW South Atlantic: space/time variability and sea surface temperatures. Cont Shelf Res 29(17):2061-2068

Lü X, Qiao F, Xia C, Zhu J, Yuan Y (2006) Upwelling off Yangtze River estuary in summer. J Geophys Res Oceans 111(C11). https://doi.org/ 10.1029/2005JC003250

Moore JK, Abbott MR, Richman JG (1997) Variability in the location of the Antarctic Polar Front $\left(90^{\circ}-20^{\circ} \mathrm{W}\right)$ from satellite sea surface temperature data. J Geophys Res 102(C13):27825-27834

Moore JK, Abbott MR, Richman JG (1999) Location and dynamics of the Antarctic Polar Front from satellite sea surface temperature data. J Geophys Res 104(C2):3059-3074

O’Neill LW (2012) Wind speed and stability effects on coupling between surface wind stress and SST observed from buoys and satellite. J Clim 25(5):1544-1569

O'Neill LW, Chelton DB, Esbensen SK, Wentz FJ (2005) High-resolution satellite measurements of the atmospheric boundary layer response to SST variations along the Agulhas Return Current. J Clim 18(14): 2706-2723

O'Neill LW, Chelton DB, Esbensen SK (2010) The effects of SSTinduced surface wind speed and direction gradients on midlatitude surface vorticity and divergence. J Clim 23(2):255-281

Olson DB, Backus RH (1985) The concentrating of organisms at fronts: a cold-water fish and a warm-core Gulf Stream ring. J Mar Res 43(1): $113-137$

Palma ED, Matano RP (2009) Disentangling the upwelling mechanisms of the South Brazil Bight. Cont Shelf Res 29(11-12):1525-1534

Palma ED, Matano RP, Piola AR (2008) A numerical study of the Southwestern Atlantic Shelf circulation: Stratified ocean response to local and offshore forcing. J Geophys Res Oceans 113:C11010. https://doi.org/10.1029/2007JC004720

Peffley MB, O'Brien JJ (1976) A three-dimensional simulation of coastal upwelling off Oregon. J Phys Oceanogr 6(2):164-180

Pickett MH, Paduan JD (2003) Ekman transport and pumping in the California Current based on the US Navy's high-resolution atmospheric model (COAMPS). J Geophys Res Oceans 108:3327. https://doi.org/10.1029/2003JC001902 
Preller R, O'Brien JJ (1980) The influence of bottom topography on upwelling off Peru. J Phys Oceanogr 10(9):1377-1398

Rodrigues RR, Lorenzzetti JA (2001) A numerical study of the effects of bottom topography and coastline geometry on the Southeast Brazilian coastal upwelling. Cont Shelf Res 21(4):371-394

Santos F, Gomez-Gesteira M, Alvarez I (2012) Differences in coastal and oceanic SST trends due to the strengthening of coastal upwelling along the Benguela current system. Cont Shelf Res 34:79-86

Shi R, Guo X, Wang D, Zeng L, Chen J (2015) Seasonal variability in coastal fronts and its influence on sea surface wind in the northern South China Sea. Deep-Sea Res II Top Stud Oceanogr 119:30-39

Silveira ICA, Calado L, Castro BM, Cirano M, Lima JAM, Mascarenhas ADS (2004) On the baroclinic structure of the Brazil CurrentIntermediate Western Boundary Current system at $22^{\circ}-23^{\circ} \mathrm{S}$. Geophys Res Lett 31:L14308. https://doi.org/10.1029/ 2004GL020036

Silveira ICA, Lima JAM, Schmidt ACK, Ceccopieri W, Sartori A, Franscisco CPF, Fontes RFC (2008) Is the meander growth in the Brazil Current system off Southeast Brazil due to baroclinic instability? Dyn Atmos Oceans 45(3-4):187-207

Small RJ, Xie SP, O'Neill L et al (2008) Air-sea interaction over ocean fronts and eddies. Dyn Atmos Oceans 45(3-4):274-319

Smith RL (1968) Upwelling. Oceanogr Mar Biol Annu Rev 6:11-46
Spall MA (2007) Effect of sea surface temperature-wind stress coupling on baroclinic instability in the ocean. J Phys Oceanogr 37(4):10921097

Stech JL, Lorenzzetti JA (1992) The response of the South Brazil Bight to the passage of wintertime cold fronts. J Geophys Res Oceans 97(C6):9507-9520

Stramma L, England M (1999) On the water masses and mean circulation of the south Atlantic ocean. J Geophys Res 104(C9):20863-20883

Ullman DS, Cornillon PC (1999) Satellite-derived sea surface temperature fronts on the continental shelf off the northeast US coast. J Geophys Res Oceans 104(C10):23459-23478

Wang Y, Castelão RM (2016) Variability in the coupling between sea surface temperature and wind stress in the global coastal ocean. Cont Shelf Res 125:88-96

Wang Y, Castelão RM, Yuan Y (2015) Seasonal variability of alongshore winds and sea surface temperature fronts in Eastern Boundary Current Systems. J Geophys Res Oceans 120(3):2385-2400

Woodson CB, Litvin SY (2015) Ocean fronts drive marine fishery production and biogeochemical cycling. Proc Natl Acad Sci U S A 112(6):1710-1715

Xie SP (2004) Satellite observations of cool ocean-atmosphere interaction. Bull Am Meteorol Soc 85(2):195-208 